\title{
Near-field Investigation of Ions Emitted from a Hollow Cathode Assembly Operating at Low-Power
}

\author{
George J. Williams, Jr", Matthew T. Domonkos*, Karyl J. Shand ${ }^{* *}$, \\ James M. Haas*, Lyon B. King ${ }^{* * *}$, and Alec D. Gallimore ${ }^{\dagger}$
}

\begin{abstract}
RPA and Langmuir probe measurements were made in the near-field plume on the axis of a hollow cathode assembly (HCA). High-energy ions were detected at low-powers consistent with the detection of such ions at high powers in previous investigations. The absence of a potential hill in the testing conditions suggests that an additional source of high energy ions may be charge exchange ions in the luminous region of the cathode discharge. The peaks in the RPA data tend to support this theory. In addition, it was established that the conditions in the near-field of the HCA expellent would be condusive to laser-induced fluorescence (LIF) measurement.
\end{abstract}

\section{Nomenclature}

h Debey shielding length $(\mathrm{cm})$

$\mathrm{j}_{\mathrm{si}}$ Ion saturation current flux $\left(\mathrm{A} / \mathrm{cm}^{2}\right)$

$\mathrm{m}_{\mathrm{e}}$ Mass of an electron $(\mathrm{kg})$

$\mathrm{m}_{\mathrm{i}}$ Mass of an ion $(\mathrm{kg})$

$\mathrm{n}$ Number density $\left(\mathrm{cm}^{-3}\right)$

$q$ Electron charge (C)

$\mathrm{T}_{\mathrm{e}}$ Electron Temperature $(\mathrm{K})$

$v$ velocity $(\mathrm{m} / \mathrm{s})$

$\lambda$ Mean-free-path (m)

$v$ Plasma frequency $(1 / \mathrm{s})$

\section{Introduction}

Hollow cathode assemblies (HCA's) serve as the electron emitters in many space applications such as the neutralizing of ion beams of plasma thrusters and the clamping of space structures to the ambient plasma. The same geometry of a keepered hollow cathode with low workfunction insert is also used to ionize propellant by producing high energy electrons in the discharge chamber of an ion engine.
Because of the varied applications, several studies have been completed which attempt to describe some of the anomalous phenomena observed in association with the operation of these assemblies. These anomalies include erosion of cathode potential surfaces and generation of highenergy ions which appear to be generated just downstream of the exit plane of the $\mathrm{HCA} .^{2,3,4,5}$

Of particular interest is the work of Paul Wilbur who suggests that the phenomena may result in part from a potential hill located just downstream of the cathode. ${ }^{2}$ Also, his data indicate high levels of charge exchange ions. ${ }^{4}$ While that work has primarily been concerned with high power operation as might be associated with ion thruster discharge chamber configurations, it may be of value to investigate the less physically prohibitive environment of lowpower operation.

In preparation for laser-induced fluorescence (LIF) measurements (of potentially high power cathodes and plasma discharges), probe data have been taken to

\footnotetext{
* Graduate Student, Student Member AIAA.

** Undergraduate Student, Student Member AIAA

${ }^{* * *}$ Ph. D, Member AIAA.

${ }^{\dagger}$ Director of Lab and Associate Professor, Senior Member AIAA.
}

Copyright $\mathbb{C} 1998$ by George J. Williams, Jr.

Published by The American Institute of Aeronautics and Astronautics with permission. 
characterize an HCA operating at a relatively low power. The objective of this investigation was to quantify the number density of the ions in the region within a few centimeters of the cathode orifice and to measure the relative energy of the ions in this region.

\section{Apparatus}

\section{Cathode}

The hollow cathode assembly (HCA) shown in Fig. 1, provided to the University of Michigan by NASA LeRC, was used in these experiments. The physical characteristics of this HCA are given in Table 1 .

In order to better approximate the ambient conditions around the keeper of an ion engine, an anode electrode was used. The stainless steel anode is shown in Fig. 2 . Four $7 \mathrm{~cm}$ axial slits were cut to facilitate observation of cathode operation, alignment of probes, and future LIF measurements. The diameter of 6.35 centimeters was chosen to facilitate comparison of data with previous investigations of ion velocities. ${ }^{3,4}$ Tests were performed with and without the anode electrode.

Figure 3 summarizes the electrical circuit and instrumentation. The heater power supply was used for cathode conditioning and to facilitate ignition. The cathodekeeper discharge was initiated and maintained using a $3 \mathrm{~A}, 55 \mathrm{~V}$ DC power supply. The cathode-keeper discharge was operated in current control mode. The current and voltage measurements were executed using digital multimeters with NIST traceable calibrations.

\section{Langmuir probes}

Two Langmuir probes with tungsten wire collectors were used in a planar probe configuration. A guard ring electrode (roughly $0.25 \mathrm{~cm}$ in diameter, $0.04 \mathrm{~cm}$ thick and $2 \mathrm{~cm}$ exposed length) was used initially. This shield was ramped to the same voltage as the probe but no current was collected from it. The driving and signal collection circuits are given in Fig. 4 .
During testing, it was noted that the shield had no noticeable effect on the data. (It was verified that a signal could be collected through it. Indeed, it provided excellent current vs. voltage traces at several centimeters from the cathode.)

The second probe was constructed subsequent to initial testing in order to provide interrogation within $0.5 \mathrm{~cm}$ of the HCA. The guard ring was eliminated to minimize perturbation of the plasma. Also, erosion of the probe in this high-density, high-temperature region could affect both probe and cathode operation. Erosion was observed on the shield of the large probe and use of this probe was subsequently restricted to regions greater than $0.5 \mathrm{~cm}$ downstream of the keeper orifice.

The Langmuir probes are subject to four "sheath" effects: deviation from quasineutrality, plasma density perturbation, ion energy depletion, and electron energy perturbation. ${ }^{7}$ The significance of these effects depends on the mean-free-path, $\lambda_{m}$, of the plasma, which is in turn from calculated measurements of these probes. Density disturbances depend on the solid angle at which the ion can impact the probe. In general, if the probe radius, $r_{\pi}$, and sheath thickness, $h$, are significantly less than the mean free path, $\lambda_{m}$, this effect is negligible. Similarly, if $\mathrm{h} \ll<\lambda_{\mathrm{m}}$, which implies there are no collisions in the sheath, the deviation from quasineutrality can be neglected. ${ }^{7}$

To avoid disturbing the energy distributions, the probe radius must also be much smaller than the mean free path. This arises from the fact that ion depleting collisions with the probe must be replaced in the local plasma by collisional ionization or ion flux.

Consistency is checked by calculating the mean free path using the data collected by the probes. The mean free path can be expressed as a function of mean velocity and plasma frequency: ${ }^{8}$ 


$$
\lambda_{\mathrm{m}}=\frac{\mathrm{v}_{\mathrm{e}}}{v_{\mathrm{i}}}
$$

The mean velocity can be taken from the ion saturation current:

$$
\bar{v}=\frac{4 i_{s i}}{q A m_{i}}
$$

The plasma frequency is a function of electron temperature and number density:

$$
v_{i i}=1.8 \cdot 10^{-9} \sqrt{\frac{m_{e}}{m_{i}}} \frac{n_{e}}{T_{e}^{3 / 2}} .
$$

The sheath thickness can be approximated as

$$
h=6.9\left(\frac{T_{e}}{n_{e}}\right)^{1 / 2}
$$

Retarding Potential Analyzer

A retarding potential analyzer (RPA), developed at the Moscow Aviation Institute (MIA), was used to measure ion energy distributions. ${ }^{9}$ The RPA is shown schematically in Fig. 5. Generally, the probe is operated with the ion retarding grid closest to the collector electrode. However, in order to minimize secondary electron current, the probe was operated with the ion retarding grid upstream of the electron retarding grid. The RPA was used as illustrated schematically in Fig. 6.

\section{Vacuum Facility}

These experiments were conducted in the Cathode Test Facility (CTF) at the Plasmadynamics and Electric Propulsion Laboratory at the University of Michigan. A photograph of the facility is given in Fig. 7. The CTF has an inside diameter of 60 $\mathrm{cm}$ and a length of $245 \mathrm{~cm}$. A $41 \mathrm{~cm}$ diameter cryogenic vacuum pump was used to maintain a high vacuum in the chamber during testing, and the base pressure was approximately $7 \times 10^{-6} \mathrm{~Pa}$. The pump speed on Xe was approximately $1500 \mathrm{~L} / \mathrm{s}$, and operating pressures ranged from $2.7 \mathrm{x}$
$10^{-3}$ to $5.3 \times 10^{-3} \mathrm{~Pa}$. The pressure was measured using a cold cathode gage.

Research grade xenon (99.999\%) was supplied to the cathode via the propellant feed system illustrated in Fig 8 . Electropolished stainless steel tubing 0.64 $\mathrm{mm}$ in outer diameter was used with ultra high vacuum metal gasket seals at all junctions. A capacitance manometer was used after alterations to the feed system in order to quantify the leak rate. The flow rate was calibrated using a bubble flow meter over the range from 1 to $5 \mathrm{sccm}$, and the error in the flow rate measurement is approximately constant at $\pm 0.07 \mathrm{sccm}$ over the range of flow. The delivery pressure of the regulator was set to $253 \mathrm{kPa}$ (22 psig), and the flow rate was controlled using a needle.

\section{Experimental Procedures}

Most of the experimental procedures described in this section were motivated by experience with the Space Station Plasma Contactor program. ${ }^{1,10}$ Using essentially the same methods is the best possible means to achieve similar lifetimes and provides continuity to the research effort.

\section{Feed System Bake-Out}

After any modifications to the feed system where the system would be exposed to the atmosphere, such as Xe bottle replacement, the feed system would be baked-out at vacuum. The goal of this procedure was to expel most of the contaminants that adhere to the feed system surfaces. First the system was evacuated to high vacuum for at least 12 hours. Heater tape, wound about the feed system tubes and fittings, was then activated for a minimum of 24 hours. The feed system was allowed to return to room temperature before continuing.

\section{Feed System Evaluation}

After the bake-out, the leak rate of the feed system was determined. This was done by closing the feed system to vacuum and monitoring the pressure and temperature of the system for at least 24 hours. The gas 
temperature in the feed system was assumed to be equal to the tube temperature. With an estimate of the feed system volume, the leak rate was determined and compared with the pass/fail criterion developed for space station plasma contactors. For the tests reported here, this procedure was only performed after $\mathrm{Xe}$ bottle replacement.

\section{Feed System Purge}

Regardless of the modifications to the system, just prior to cathode activation the feed system from the flow control valve through the cathode was purged at high vacuum for at least 12 hours. This evacuated the contaminants at low temperature when they are less likely to react with the cathode surfaces.

\section{Cathode Activation}

The cathodes were activated according to procedures developed previously following any exposure of the insert to atmosphere. Following this activation, only a short preheat of the cathode was necessary prior to ignition. The heater supply was turned off immediately following ignition.

\section{Positioning}

Intended to facilitate LIF measurements, the positioning of the probes in the plume of the $\mathrm{HCA}$ was accomplished primarily by axially moving the cathode. In order to use more than one probe, a swing arm was introduced to position a Langmuir probe on the center-line of the cathode orifice. This is shown schematically in Fig. 7. The cathode was mounted on a NEAT $30 \mathrm{~cm}$ translation stage.

Alignment of the Langmuir probes was facilitated by introducing a laser into the chamber which was known to be very near the centerline. The probes were then moved into the beam for alignment.

The RPA was fixed downstream of the HCA. It's alignment was completed before the facility was brought to high vacuum.

Resolution in axial and radial position was accomplished within $0.1 \mathrm{~cm}$. This was visually verified with the chamber at atmosphere and confirmed through use of the laser when at vacuum. It was possible to take multiple probe measurements without varying the $\mathrm{HCA}$ /anode operating condition.

\section{Operating conditions}

The HCA was operated over a wide range of discharge currents and voltages. The principal limitations on the output power were the flow meter $(5 \mathrm{sccm})$ and anode wiring (8A). The operating conditions are summarized in Table 2.

The current/voltage setting of the HCA without an anode electrode were chosen as those corresponding to potential applications. However, the high current operation of the HCA in a space station contactor configuration was beyond the capability of the testing facility.

In general, the operating conditions of the HCA with an anode were randomly chosen to present a mix of spot and plume modes over the range of testing capability.

\section{Results}

\section{Langmuir probe}

From Eqns. 1-3, the mean free path of the plasma varies from $4.0 \mathrm{~cm}$ to roughly 40 $\mathrm{cm}$. The sheath thickness from Eqn 4 is on the order of $5 \cdot 10^{-2} \mathrm{~cm}$. Therefore, probe data is within the thin sheath limit.

Floating potential, plasma potential, electron temperature, electron saturation current, and electron number density were determined using the Langmuir probe. The data were reduced graphically. In general, the error introduced by this method (a few percent) is significantly less than the errors introduced phenomenalogically and by the noise of the data. Therefore, errors of roughly ten percent are assumed with respect to determination of electron temperature. The error associated with electron saturation is significantly larger and the data may well be off by 50 percent. Note, however, this is not indicated in the plots of plasma potential. Also note, that 
errors of this magnitude are acceptable in meeting the objectives of this investigation. The following discussion is divided into section on the HCA without an anode and the HCA with an anode.

The cahtode was maintained at ground potential. Therefore, plasma potential and the ion potentials measured below are measured with respect to ground.

\section{Without anode}

Two operating conditions were selected to represent the testing without an anode. Both were taken from an application requiring a $\mathrm{HCA}$ to provide an ambient plasma for space environment simulation. As noted in Table 2, the same current was maintained for each and the flow rate was varied from 2.3 to $4 \mathrm{sccm}$. Both conditions are in spot mode, but one with the lower flow rate is close to transitioning.

Langmuir probe data for $\mathrm{HCA}$ operation without the anode is seen in Fig. 10. Note that the small Langmuir probe was used for all measurements closer than $0.5 \mathrm{~cm}$ to the keeper. For the $2.3 \mathrm{sccm}$ case, there was a significant change in electron temperature as measured by the smaller probe. As the reason for this is unclear, the error associated with that measurement is correspondingly increased. Note, however, that number density and plasma potential data for both probes are in agreement with each other. The increase in electron temperature for the $2.3 \mathrm{sccm}$ cae is due to the colse proximity of this operating condition to plume mode. Electron temperature data for the $4 \mathrm{sccm}$ case appear to transition smoothly between use fo the two probes

Of particular note is that there is no noticeable region of high potential in the exit region. This is consistent with previous studies which indicate that the "potential hill" is preset primarily in plume mode. ${ }^{2}$ Indeed, when the $\mathrm{HCA}$ was operated at $2 \mathrm{~A}$ keeper current, the hill was detected.

\section{With anode}

Operation of the HCA with an anode was limited in power by the propellant feed system and the wiring. However, the moderate $6 \mathrm{~A}$ operation was instructive in predicting trends which might be observed in later studies. Because the keeper electrode is integral to the HCA, operation without a keeper (as in the NSTAR FMT configuration) was not possible except to have the keeper off. This resulted in a clear plume mode operation. The difference between these two low power cases might be instructive as to the elimination of erosion in ion engines which have gone to keepered discharge cathode configurations.

Note in Fig. 11 that the electron temperature of the plume mode is seen to increase significantly with distance from the keeper. The slight increase associated with all cases is consistent with the idea that as the distance to the probe increases, only more energetic electrons are collected. The greater increase of the plume mode case indicates that there is greater loss of moderately energetic ions out of the centerline (i.e. to the anode).

The plasma potential is again roughly constant and is slightly above the discharge voltage. However, there is a dip at about 1 $\mathrm{cm}$ from the keeper for both cases. Because of the harsh plasma environment, it was not possible to use the small probe to obtain data closer than $0.5 \mathrm{~cm}$. It was expected that the potential of the plume mode would increase significantly. This would have been consistent with the high level of erosion observed in the $2000 \mathrm{hr}$. NSTAR ion thruster wear test.. The absence of such a rise may be due to the uncertainty associated with the plasma potential measurement.

Of particular interest to the ongoing effort to do LIF in the exit region of the cathode is the high number density extending out several centimeters from the keeper. While the plume mode drops more quickly, it is reasonable to assume that LIF is possible in the first centimeter or two downstream of the keeper as tests have been performed at these densities elsewhere. ${ }^{11}$ 
$\underline{\text { RPA }}$

Figure 12 shows the collected ion current density as a function of ion potential relative to the plasma for the same HCA conditions as given in Fig. 10 for the 4 sccm case. Four positions downstream of the keeper are given. On the same graphs are the derivatives of these traces which show the peaks in ion energy. Despite the inherent noisiness of the numerical derivatives of the data, it is clear that there are well defined peaks of energetic ions. Presentation of the data in this form was deemed preferable to curve-fitting or smoothing because those methods can induce significant errors. ${ }^{12}$

The peaks clearly move to higher energies as the measurement is moved downstream. In this fashion, the trend in ion energy mirrors that of the electron energy. Note that the vertical scale of the changes with position so that the high energy ions detected at $10 \mathrm{~cm}$ may actually be part of the trace at $2 \mathrm{~cm}$ but are dwarfed by the large peaks at the beginning of the trace. Note that theree is a peak near the high voltage end of the first trace. This may be an artifact fo the smoothing routine used on the raw current/volage traces. A more sophisticated means of averaging than 11point box averaging may be advised.

The presence of peaks significantly above the discharge voltage is highlighted also in Fig 13. Data is presented for the spot and plume mode cases described above. As expected, the plume mode case exhibits higher energy ions (it's at a higher discharge voltage) and there is a high energy presence well downstream of the keeper. Again, the end effects of the probe ramps almost obscure the fact that he high energy ions are present in almost the order of magnitude at $3 \mathrm{~cm}$ as they are at $5 \mathrm{~cm}$. However, nearly all of the lower energy ions are no longer present. Note also that the slight increase in current (which is impossible in theory) may be due to collection of electrons as the retarding voltage is initially increaed.

The high-energy peaks may result from charge exchange collisions between multiply charged ions. ${ }^{12}$ Note the relative spacing in the spot mode case (13 a and $b$ ). Whatever collisions are occurring would have to take place in the luminous part of the discharge (i.e. very near the keeper exit). This explanation is consistent with the earlier data as well.

\section{Conclusions}

RPA and Langmuir probe measurements indicate that the region within the one or two centimeters downstream of the keeper have high energy ions as well as those further away. The most probable explanation for this is that there is significant charge exchange near the keeper orifice which "freezes" in a significant fraction of high-energy ions. Since no probe measurements were made adequately near this region, it is impossible to say whether the mean-free-path decreases to the point where this exchange is likely.

Of particular interest to this investigation is the affirmation that the number densities and energy distributions in the region near the keeper orifice are of an order conducive to LIF. Indeed, similar probe measurements may support the initial LIF testing to facilitate scanning ranges in order to detect the large distribution of ion velocities that these data indicate.

The new cathode test facility performed nominally. Despite by-weekly cyclings between atmosphere and vacuum, the facility constantly maintained $a$ base pressure of roughly $10^{-7}$ Torr.

\section{Acknowledgments.}

This work was made possible by the continuing support of NASA LeRC and the personnel associated with the On-Board Propulsion Branch. Of special support has been $M$. Patterson. The research has been carried out under NASA Grants NAG31572 and NGT-3-52311. The authors would also like to thank the other students in the PEPL group for their assistance and support. 


\section{References}

${ }^{1}$ Patterson, M. J., Verhey, T. R., Soulas, G., and Zakany, J., "Space Station Cathode Design, Performance, and Operating Specifications," IEPC Paper No. 97-170, 25th International Electric Propulsion Conference, Cleveland, $\mathrm{OH}$, Aug. 1997.

${ }^{2}$ Williams, J. D., "An Experimental Investigation of Hollow Cathode-Based Plasma Contactors," NASA CR-187120, May 1991.

${ }^{3}$ Friedly, V. J., and P. J. Wilbur, "High Current Hollow Cathode Phenomena," Journal of Propulsion and Power, 8 (3) 1992, 635-643.

${ }^{4}$ Siegfried, D. E., and P. J. Wilbur, "An Investigation of Mercury Hollow Cathode Phenomena," AIAA-78-705, 13th International Electric Propulsion Conference, San Diego, CA, April, 1987.

${ }^{5}$ Kameyama, I., and P. J. Wilbur, "Characteristics of Ions Emitted from HighCurrent Hollow Cathodes," IEPC-93-023, 23rd International Electric Propulsion Conference, 1993.

${ }^{6}$ Monterde, M. P., et al, "Kaufman-type Xenon Ion Thruster Coupling Plasma:
Langmuir Probe Measurements," J. Appl Phys D, 30 (1997) 842-855.

${ }^{7}$ Schott, L., "Electrical Probes,"Plasma Diagnostics, W. Lochte-Holgreven ed., AIP Press, Woodbury, NY, 1995 pp 668725.

${ }^{8}$ Jahn, R. G., Physics of Electric Propulsion, McGraw-Hill, New York, pp 45-65.

${ }^{9}$ Marrese, C., et al, "An Investigation of Stationary Plasma Thruster Performance with Krypton Propellant," AIAA-95-2932, 31st Joint Propulsion Conference, San Diego, CA, July, 1995.

${ }^{10}$ Sarver-Verhey, T. R., "Extended Test of a Xenon Hollow Cathode for a Space Plasma Contactor," NASA Contractor Report 195402, Nov. 1994.

${ }^{11}$ Cedolin, R. J., et al, "Laser-Induced Fluorescence Diagnostics for Xenon Hall Thrusters," AIAA-96-2986, 32nd Joint Propulsion Conference (July, 1996).

${ }^{12}$ King, L. B., "Ion Energy Diagnostics in thme of an SPT-100 from Thrust Axis to Back Flow," AIAA-98-3641, 34th Joint Populsion Conference, Cleveland, $\mathrm{OH}$ July, 1998.

Table 1 Physical Characteristics of the Hollow Cathode Assembly

\begin{tabular}{|l|c|}
\hline Cathode diameter & $0.635 \mathrm{~cm}$ \\
\hline Cathode orifice diameter & $0.08 \mathrm{~cm}$ \\
\hline Cathode orifice chamfer & $45 \mathrm{deg}$. \\
\hline Keeper diameter & $1.5 \mathrm{~cm}$ \\
\hline Keeper orifice diameter & $0.3 \mathrm{~cm}$ \\
\hline Keeper to cathode spacing & $0.1 \mathrm{~cm}$ \\
\hline
\end{tabular}


Table 2: HCA Operating conditions

\begin{tabular}{|c|c|c|c|c|c|}
\hline $\begin{array}{c}\text { Keeper } \\
\text { Current } \\
(\mathrm{A})\end{array}$ & $\begin{array}{c}\text { Keeper } \\
\text { Voltage } \\
\text { (V) }\end{array}$ & $\begin{array}{c}\text { Anode } \\
\text { Current } \\
(\mathrm{A})\end{array}$ & $\begin{array}{c}\text { Anode } \\
\text { Voltage } \\
\text { (V) }\end{array}$ & $\begin{array}{c}\text { Mass Flow } \\
\text { Rate } \\
(\mathrm{sccm})\end{array}$ & $\begin{array}{c}\text { Facility } \\
\text { Pressure } \\
\left(10^{-5} \text { Torr }\right)\end{array}$ \\
\hline \hline 4.03 & 13.07 & NA & NA & 2.3 & 1.5 \\
\hline 4.03 & 11.61 & NA & NA & 4.0 & 3.1 \\
\hline 2.15 & 10.24 & 4.00 & 16.90 & 4.0 & 2.9 \\
\hline 0.00 & 0.00 & 6.05 & 28.1 & 4.0 & 3.0 \\
\hline
\end{tabular}

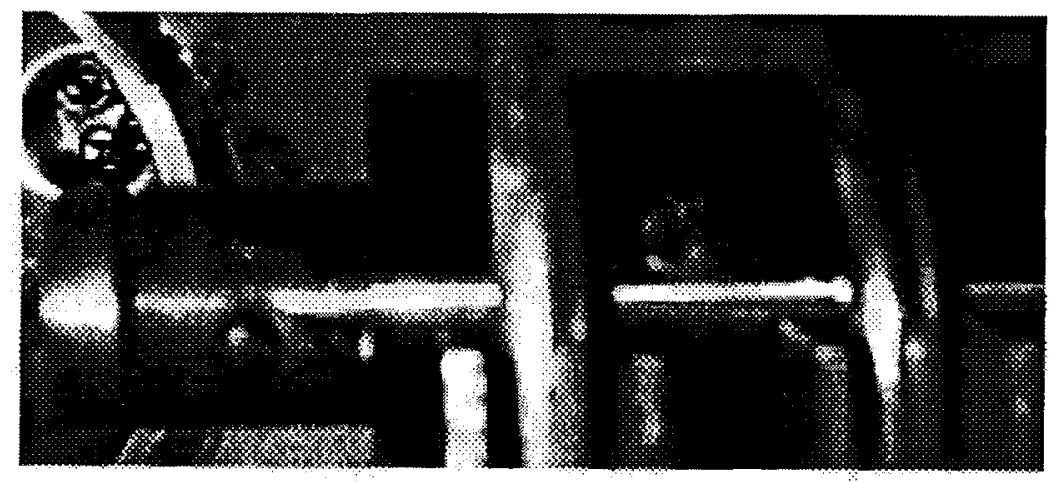

Figure 1 Hollow Cathode Assembly.

Fig 2 Anode

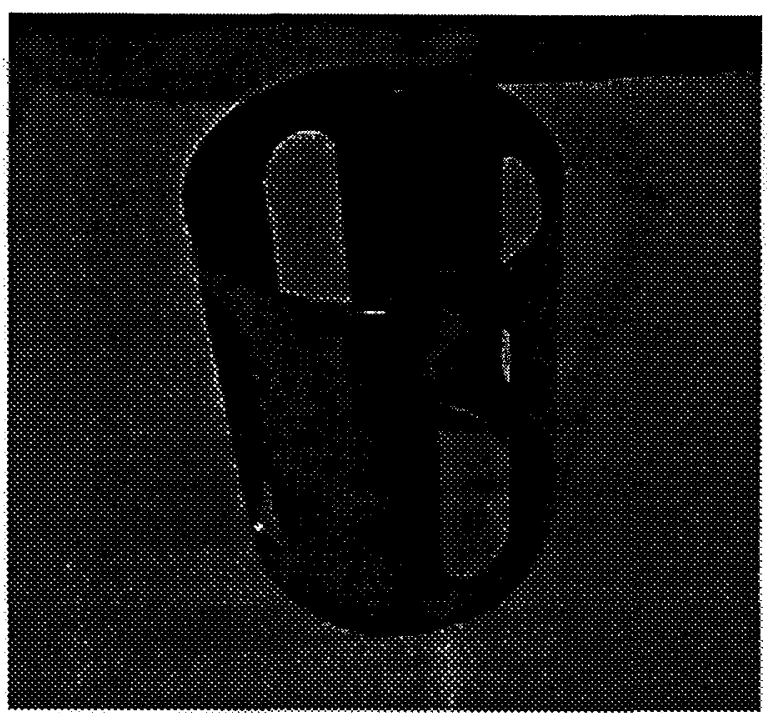

Fig. 2 Anode.

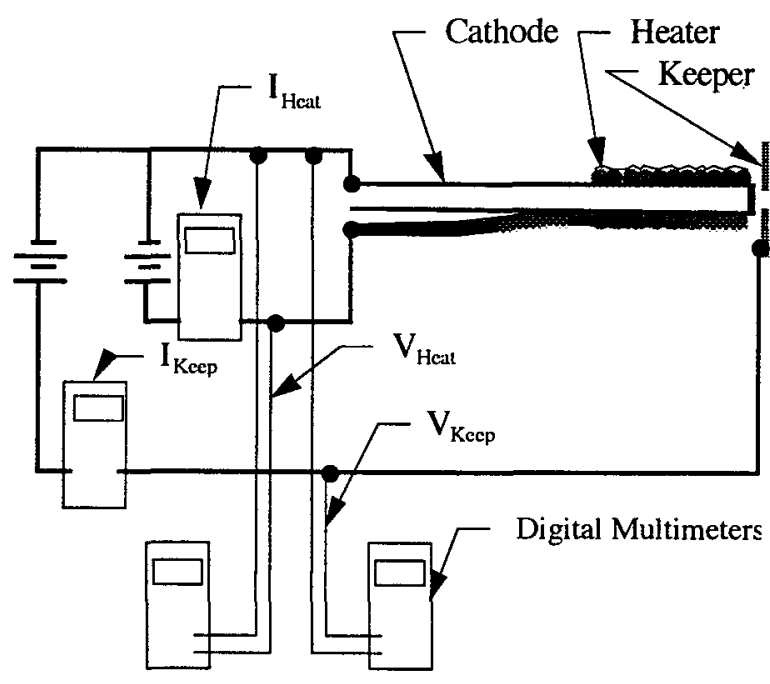

Fig. 3 Schematic of HCA electrical connections 


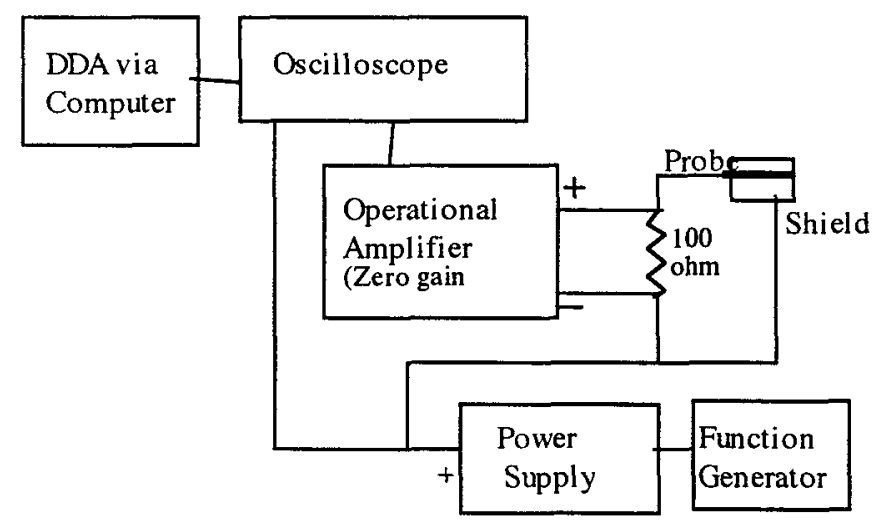

Fig. 4 Schematic of Langmuir probe circuitry.

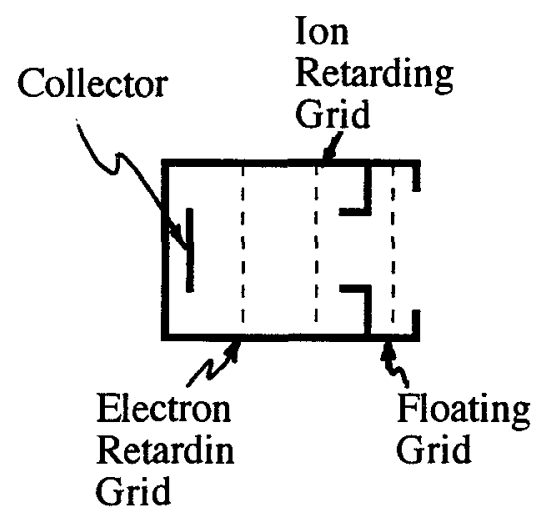

Fig. 5 Diagram of the RPA.

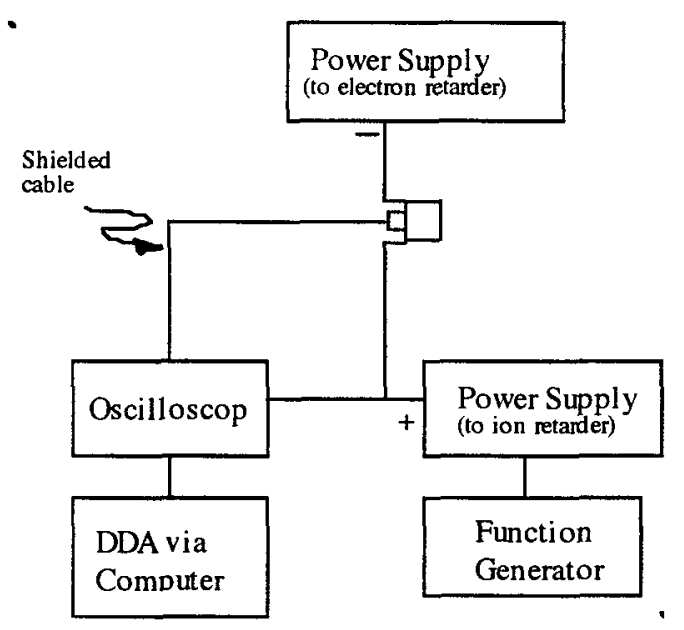

Fig. 6 Electrical schematic of the RPA. 


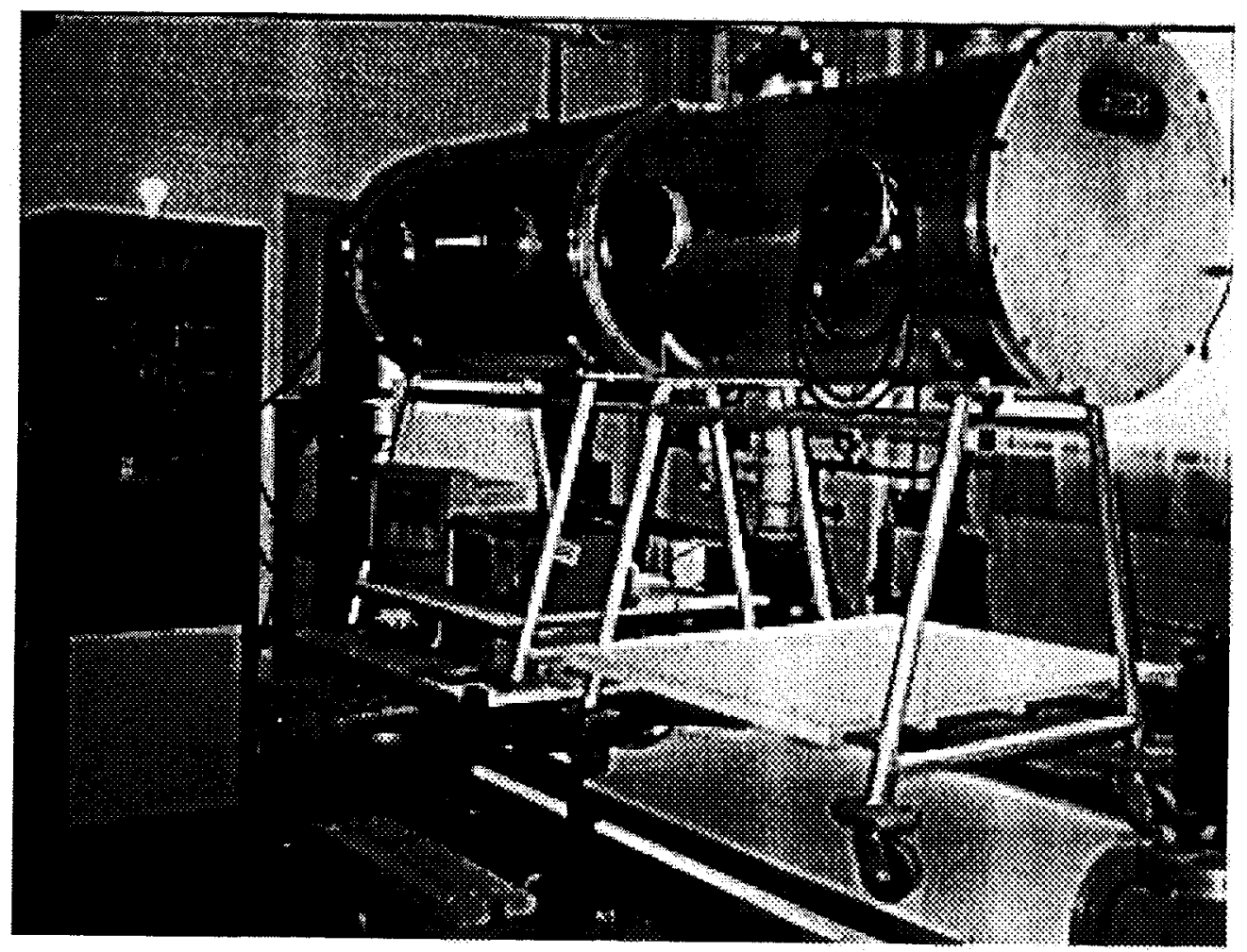

Fig. 7 Photograph of the CTF at PEPL.

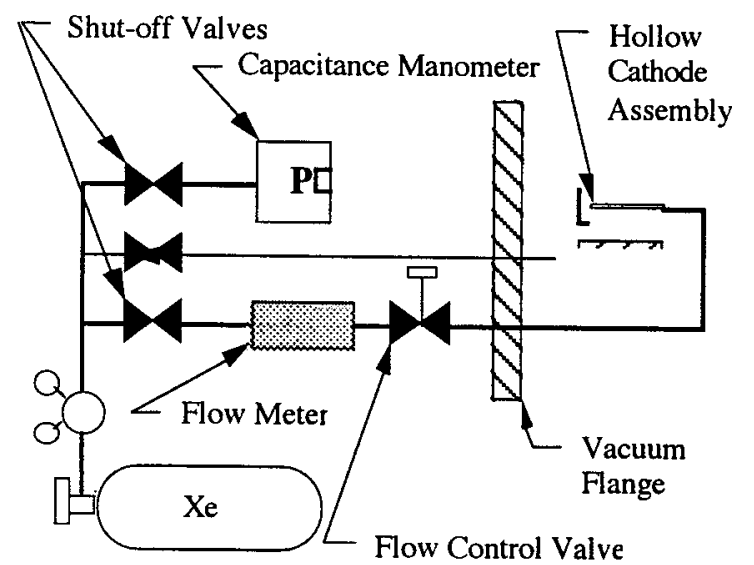

Fig. 8 Schematic of the propellant feed system

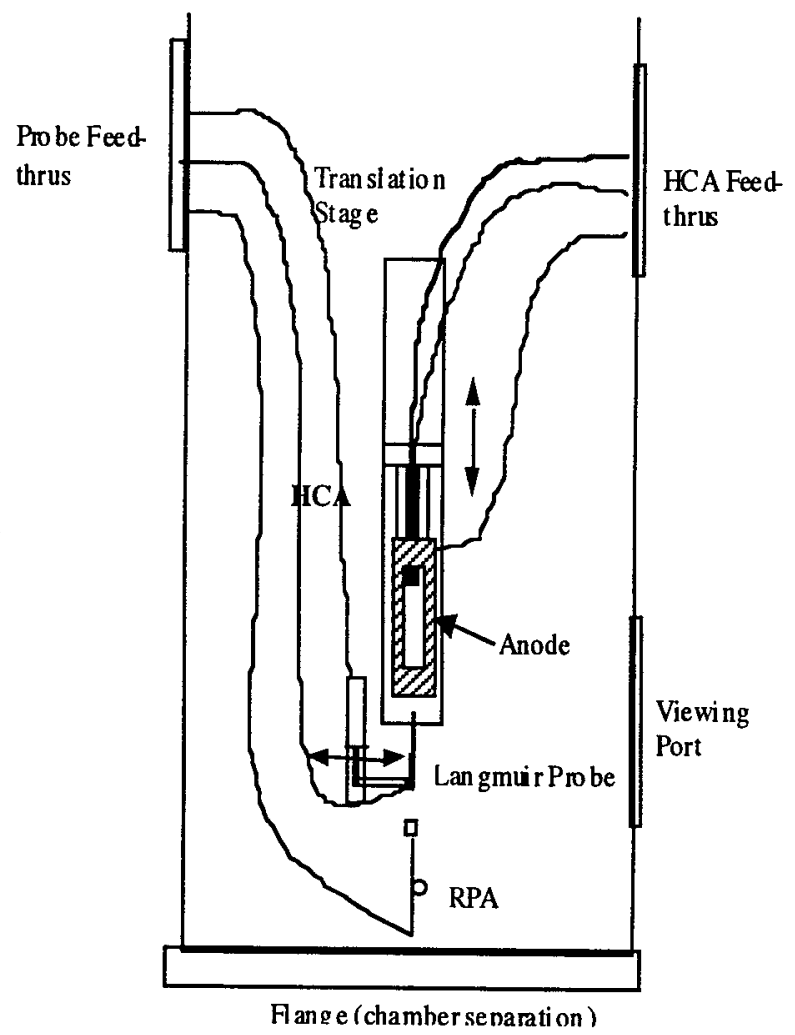

Fig. 9 Diagram of testing apparatus. 

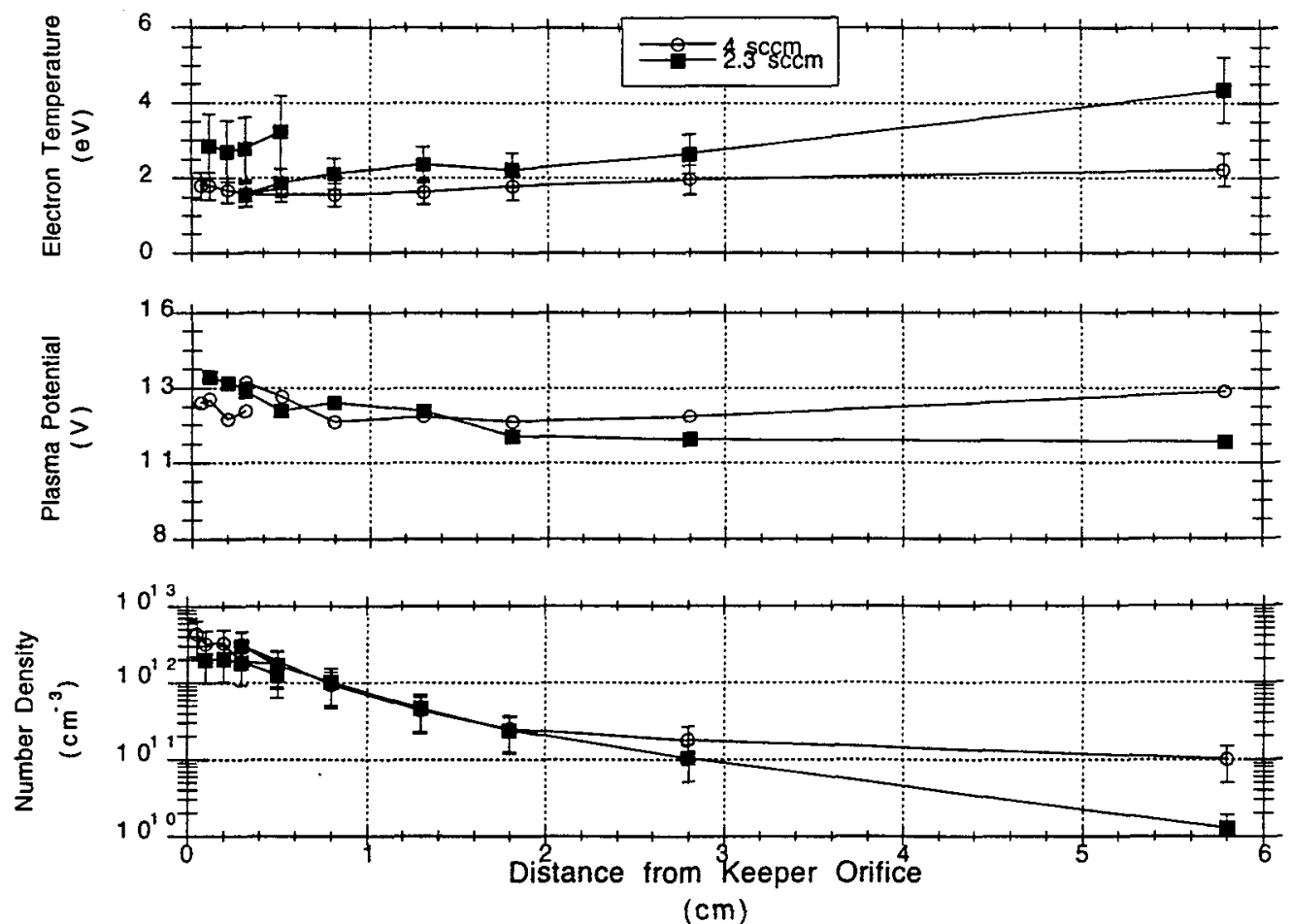

Fig. 10 Langmuir probe data for the HCA operating without an anode. Note that all data inside of $5 \mathrm{~mm}$ was taken with the small probe.
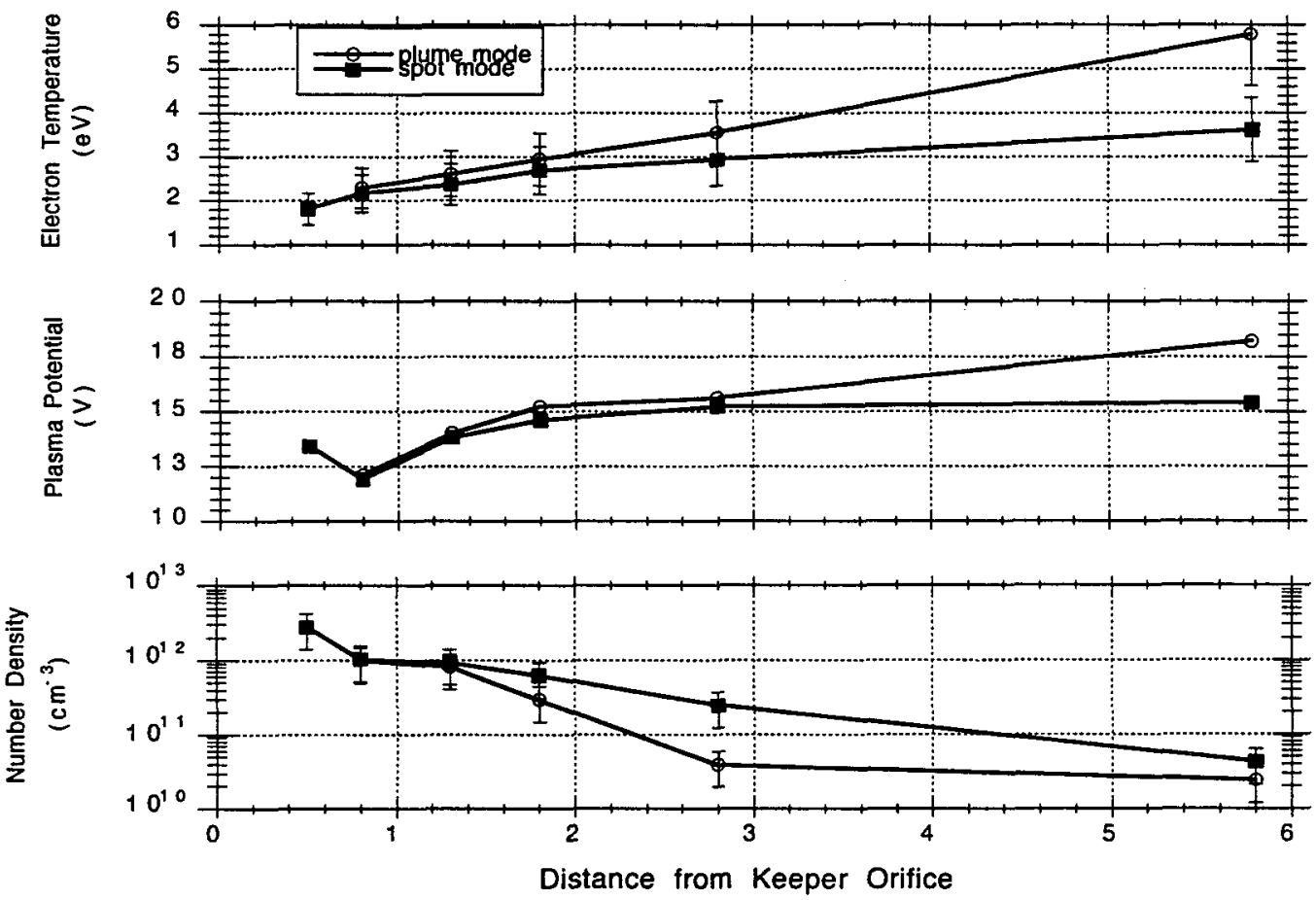

Fig. 11 Langmuir probe data for the HCA run with the anode. 


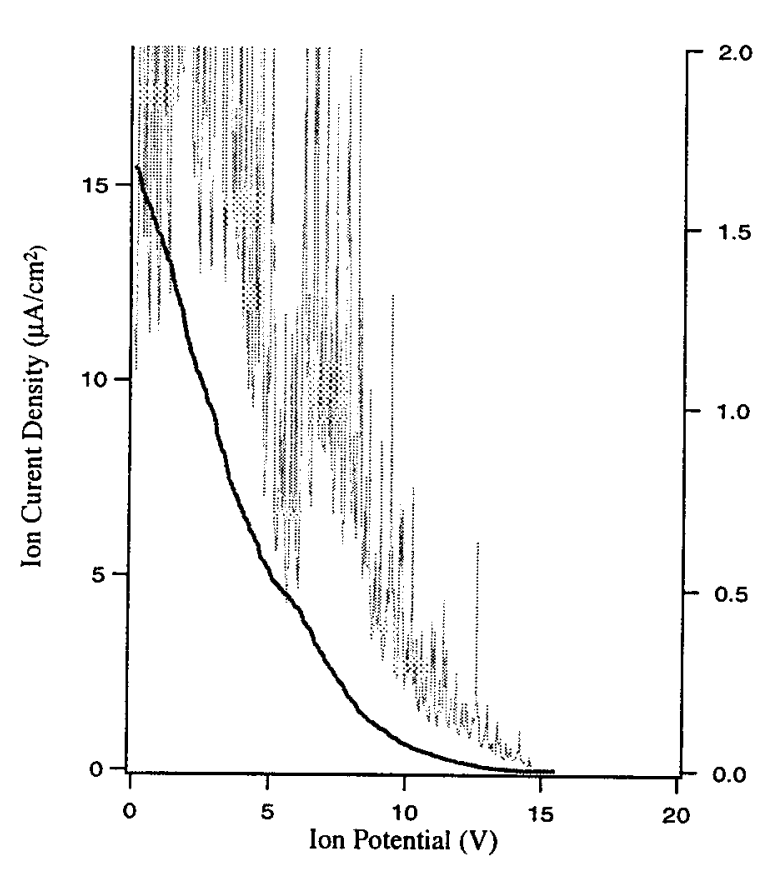

a. $2 \mathrm{~cm}$ downstream of keeper

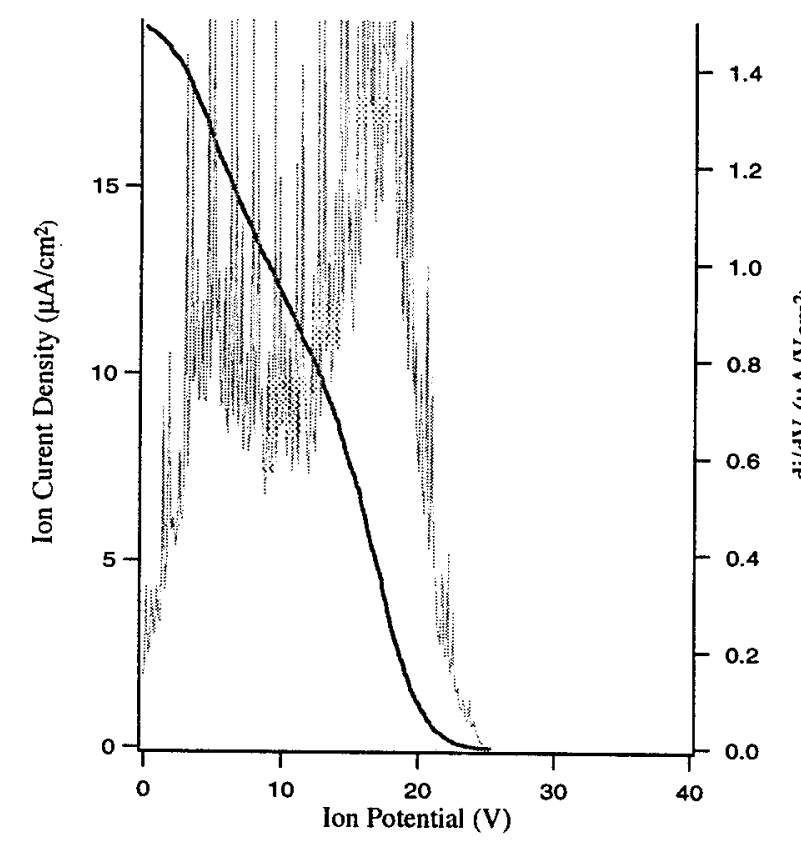

c. $5 \mathrm{~cm}$ downstream of keeper

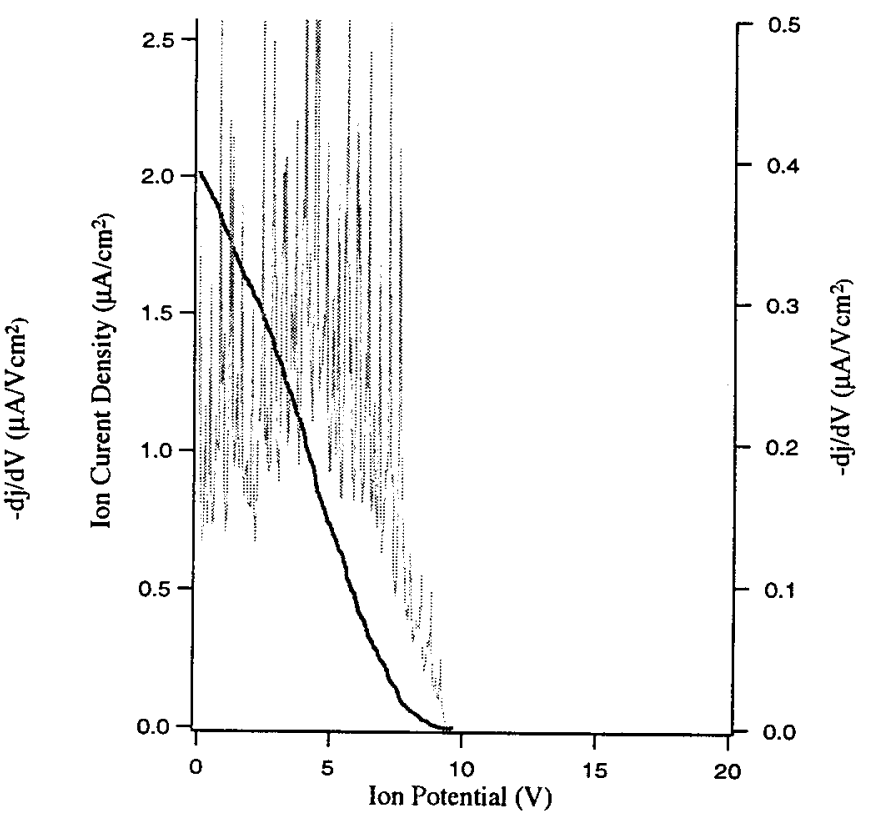

b. $2.5 \mathrm{~cm}$ downstream of keeper

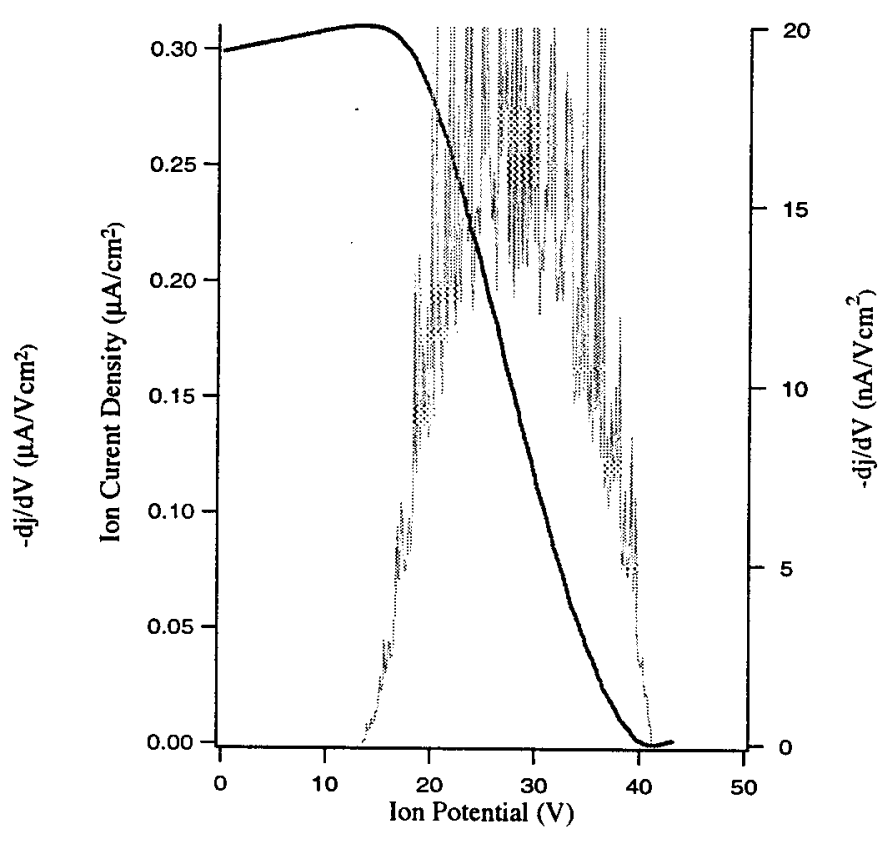

d. $10 \mathrm{~cm}$ downstream of keeper

Fig. 12 RPA data taken downstream of the HCA operating at $4 \mathrm{~A}, 10 \mathrm{~V}$ with $4 \mathrm{sccm}$ Xe flow. 


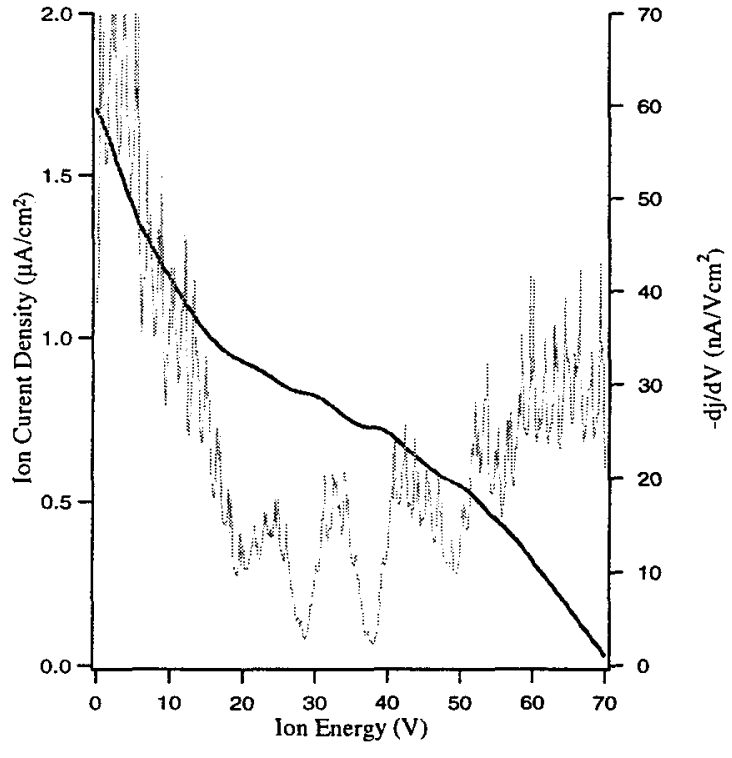

a. RPA $3 \mathrm{~cm}$ downstream of keeper. (Spot mode.)

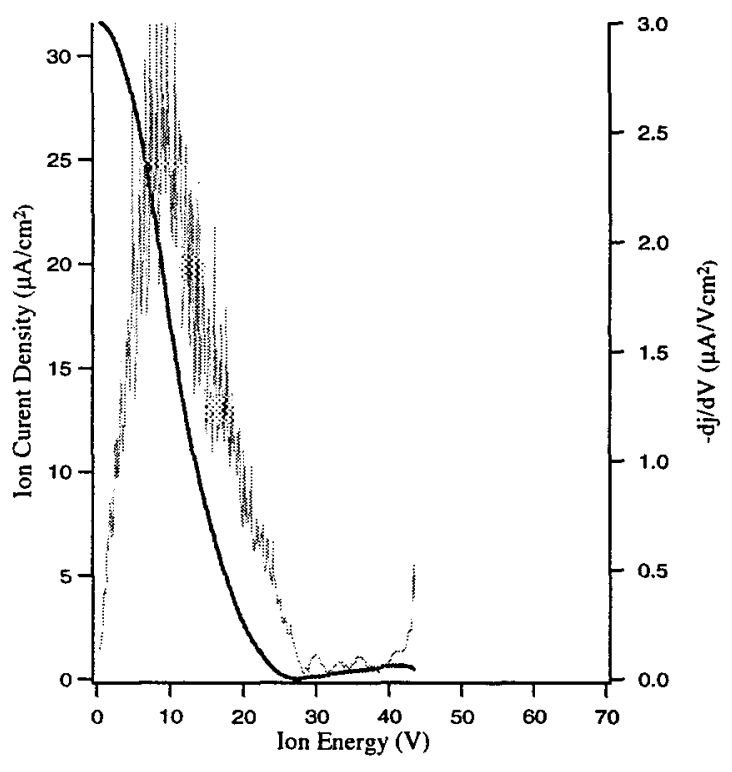

c. $3 \mathrm{~cm}$ downstream of keeper (Plume mode.)

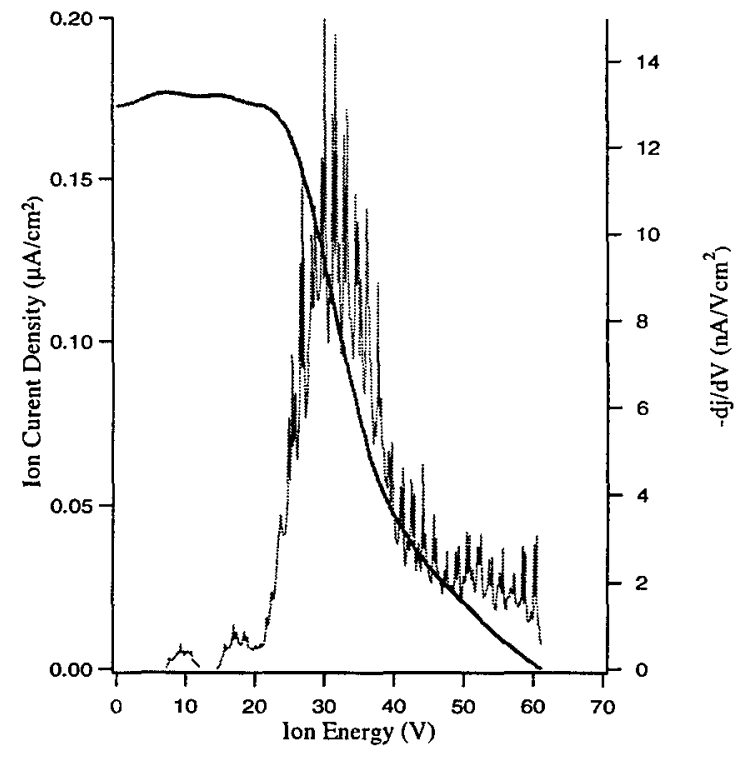

b. $5 \mathrm{~cm}$ downstream of keeper. (Spot mode)

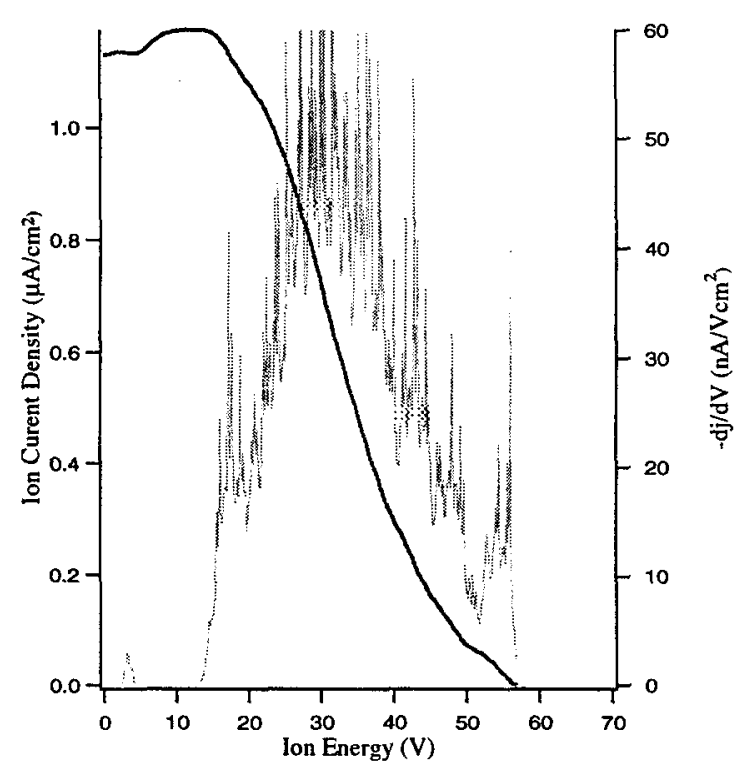

d. $5 \mathrm{~cm}$ downstream of keeper (Plume mode.)

Fig. 13 RPA data for HCA operating at $6 \mathrm{~A}$ with an anode electrode. 